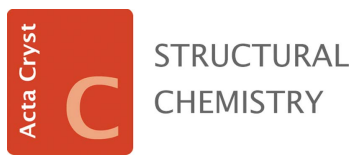

ISSN 2053-2296
Keywords: book review; environmental chemistry; soil; water; air; atmosphere; pollution; environmental processes

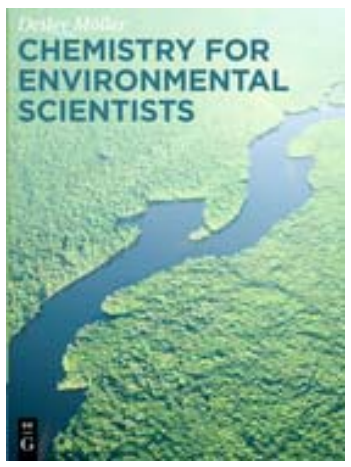

\section{Chemistry for Environmental Scientists. By Detlev Möller. De Gruyter, 2015. Paperback, Pp. XIV+380. Price EUR 69.95, USD 98.00, GBP 52.99. ISBN 9783110409994.}

\author{
Marc Hebrant* \\ Université de Lorraine, LCPME, UMR 7564, Villiers-lès-Nancy, F-54601, France, and CNRS, LCPME, UMR 7564, \\ Villiers-lès-Nancy, F-54601, France. *Correspondence e-mail: marc.hebrant@univ-lorraine.fr
}

As indicated by its title, the book 'Chemistry for Environmental Scientists' aims at covering a very broad field of knowledge. After a short and general introduction, it is divided in four chapters, namely 'Chemistry under environmental conditions', 'Fundamentals of physical chemistry', 'Chemistry of the elements and its [sic] compounds in the environment' and 'Chemical processes in the environment'. The first chapter gives mainly basic physicochemical concepts on matter and its states. Some examples relating to air, atmosphere, 'water and waters' (i.e. pure water and natural waters), soils and dusts are given. The second chapter concentrates on physical chemistry, thermodynamics and kinetics, though the discussed concepts of general chemistry are those usually taught at the bachelor degree level in chemistry. This second chapter is completely independent of the others.

The third chapter deals with chemistry in the atmosphere and in the condensed phases of $\mathrm{H}, \mathrm{O}, \mathrm{N}, \mathrm{S}, \mathrm{C}$, halogens, phosphorus, metal and metalloids. The final chapter deals with numerous subjects, such as chemical evolution, the formation of the earth, volcanism, photosynthesis, atmospheric chemistry and radioactivity.

Although this book deals with a very interesting field of science, it is difficult for me to recommend it. Indeed, the way the species are written is not in the way recommended by the International Union of Pure and Applied Chemistry (IUPAC) and in many cases I simply could not understand the things that were written. [What are the species $\mathrm{H}$ and $\mathrm{OH}$ in solution? I would have said before (and after) reading this book that they don't exist in the terrestrial environment. $\mathrm{H}$ and $\mathrm{OH}$ are only two examples of improbable species among numerous others in the book.] Equilibrium constants are also not calculated as recommended by IUPAC and the chemical activity concept is clearly not considered. What I would understand as radical species are not indicated in the normal way (i.e. with a superscript dot) in most cases, so it is hard to understand the species in question. Moreover, there are some typographical errors which are offputting (for instance, $\mathrm{Mg}^{2+}$ is not the reduced species of $\mathrm{Mg}$ ).

There might be some useful information in this book but the problems described in the preceding paragraph make the reader wary of placing undue reliance on its content. 